\title{
Editorial
}

\section{Pedagogy Today: The Challenges of the Present. The Richness and Plurality of Contemporary Research}

Michele Corsi, Massimiliano Stramaglia and Mathieu Deflem ${ }^{*}$

The editors of this journal chose, for all of 2020, to dedicate the entire year to contemporary pedagogical research. We report on the call we launched in the second half of 2019.

We received, as expected, a large number of scientifically robust responses, as demonstrated by the numerous articles that we published in the previous issue. This issue proceeds in the same way, but with some differences.

In fact, both issues are of such a magnitude as to justify the voluminous nature of the pages that they contain.

A second observation.

Under the pressure of the pandemic, which is real, normal, rational and, moreover, emotional and psychologically devastating, we dedicated the editorial of the previous issue to the, in many ways, cursed and disturbing "suspended time" of the coronavirus; a global event, moreover, which is both articulated and jagged, controversial and nevertheless politicized and full of contrasts, which does not yet seem to be ending. Just think of the ongoing conflict between the US, China and the World Health Organization. With some justifications these are also understandable. Or at least in part. Almost obscuring the specific nature of the contributions received, also with regard to the editorial. And giving readers almost total freedom of reflection, judgement, and, therefore, of possible hermeneutic and perspective interpretations.

In this issue, however, we want to draw attention to the overall theme of these two files. Using the contributions published here as a magnifying glass, a critical commentary, of occupation of the present and a launch into the future, also of the articles of the first issue of this 2020. So as to contain them and observe them globally, both the former and the latter. With an all-encompassing gaze capable of bearing witness to the question: where is current pedagogy going? Italian and world-wide; at least pedagogy in the most cultured and scientifically best equipped countries. What are its lines of research, their

\footnotetext{
* Professor of Sociology at the University of South Carolina. E-mail: m@mailbox.sc.edu.
} 
"practical" repercussions, their impact on the needs and efforts of the people of this current time?

Faithful to our epistemological principle of a "useful" pedagogy.

That, starting from the past, and therefore from the history of pedagogy and education, carefully examine, without any type of prejudices - ideological vices or worse, the here and now of human contemporaneity, to project, into future years, its far-sighted prophecy of individual and community good.

Of another pedagogy, with a refrain that is dear to us, we do not know what to do with it. Useless, if not even harmful at times.

So much so as to deny space and visibility to pedagogy itself, and confuse it, as on the shelves of the best bookstores, with philosophy (moreover, not always of education), if not also with childcare or with a limping science of nutrition of a paediatric bent.

Thus, placing greater emphasis on psychology and on development, sociology, anthropology and human and social sciences in general.

Unfortunately, not all Italian pedagogy is consistent with its epistemological status. To represent, at times, a sort of unhappy and inauspicious return to an old-fashioned post-positivism. Packaged, as it is, as a science of results or an applied science à la Parsons: applied biology or old philosophy reworked, second or third row scientism à la Durkheim or as a sequel of Piaget, etc. That, while the originals are always noble and very high, even if they cannot be shared from a pedagogical point of view, copies, ugly or semi-beautiful as they may be, will always be copies. Re-issues and remakes. If not also artificial, poorly made and of little or no value.

But we want to open our hearts with hope.

As with regard to this Covid-19. Or we remain, in fact, crushed, anxious and frightened, or, as in the best tradition of Neapolitan theatre, we dare to think that sooner or later the night will end.

That the clear skies will return, after the rain.

Or the clear and bright dawn, after the dark, often black and unpleasant, of the previous hours.

However, let us put complaints to one side, even when they are due and necessary.

To focus on the best case, on the future and on the feasible: again, that is, on the useful, the usable and the practicable, like Dewey, at least on Italian pedagogy. In fact, all the contributions published here, and which we will report on, are investigations, in short, of more complex upstream research by our colleagues.

A third observation is related to the current change of pace in national pedagogy. And its passage, not always easy and understood, from a less plural and articulated investigation to an investigative richness and breadth of 
heuristic strands and tracks. Particularly in the last thirty years. As our own direct observation can testify. And which, perhaps, more "critical" colleagues could also call excessive.

Perhaps.

But a new order always is always born from an upstream disorder.

From chaos to creation.

Today's multiple lines of research are, therefore, welcome. They also connect pedagogy better with the interests of the social sciences, which can lead to fruitful cross-fertilization of themes and perspectives.

Some of these research lines will certainly need to be refined over time, to become even more pedagogical. And with other trends that can also be "combined" or unified with each other, so that they avoid being a micro-niche and achieve greater educational, scientific and prospective reach.

But we now come to this issue and to the change in theoretical exploration and practical work in the last thirty years of Italian pedagogy. But also, in territorial or geographical terms, much more than that.

In the 1970s, our local pedagogy (meaning, by it and with it, the entirety of our current four scientific-disciplinary sectors) had a prevailing focal point: the school. So much so as to make pedagogues the only, almost recognized, experts of this institution.

Such that you would not be appointed to a post as professor of this discipline if you did not have at least one monograph on your CV dealing with such a topic, namely school education under some aspect of this multifaceted crystal. And alongside it, in conjunction, either the pedagogy of the family, strictly in the singular and of a very strict Catholic bent (few, if any, lay pedagogues dealt with it) or, more importantly, the philosophy of education. The latter addressed by both sides.

Only marginally, and rarer, other types of in-depth analysis (we are referring in particular to what is M-PED/01 today): a book every now and then, although scarce, on some other topic by some more adventurous or, possibly, imaginative colleagues. Not to accuse only some of originality at the expense of others.

Pedagogy, however, often broken down with the history of pedagogy. So as to be able to move, indiscriminately, from one chair to another.

A fortiori didactics (currently M-PED/03), understood only, then, as the general theory of teaching, and nothing else. Scholastic teaching, of course. Or the initial experimental pedagogy. More common in pontifical universities, particularly in Salesian forums, where they wrote about evaluation (docimology) or orientation. Here too, mostly scholastic matters. With meagre and timid openings to the university. 
The change of pace took place at the beginning of the $90 \mathrm{~s}$, with the transformation of the Teachers' Training Colleges into Faculties of Education, and with changes to the lists of their degree courses. Like the rightful, growing attention to the dialogue between pedagogies and educational sciences.

Around 2000, with the Berlinguer reform, there was a real hermeneutic and investigative explosion even in the pedagogical context as a whole. With an unprecedented explosion of research. Of which the present selection offers a first clear demonstration.

So there are eleven different contributions to be found in these pages. With some diversifications also within. So that their number is ultimately almost double of our usual output. And this is far from the totality of what the pedagogies have produced in the last twenty years. With still others that have been emerging more recently, such as pop education, or pop pedagogy, or that of musical myths.

Nevertheless, against the background of a renascent psycho-pedagogy or a recovery, under the increasingly marked and widespread push of the phenomena of deviance, worse: of violence, of so-called street pedagogy. Dear to the most enlightened minds of the master writers of the Roman villages (Pietralata) or of the suburbs of the great cities (from Milan to Turin, to Palermo).

And so we come to this issue. And to its contributions.

We acknowledge them, obviously without any order of merit or of sectorial or sub-sectorial status. But following, as an indicator, the timing of their approval and, therefore, of their subsequent publication. With some areas, indeed, which appear here with a greater "presence", as opposed to the editorial space that they sometimes occupy in the largest pedagogical bibliography, Italian in particular: in fact, all of the articles that appear on these pages. But also worldwide.

Two issues, these, which must therefore be understood as a single volume: we have divided them only for reasons of space or "weight". Including also the contributions of foreign pedagogues in the first issue. Or of connoisseurs close to our disciplines.

Gender pedagogy in the singular and plural, with an extension to masculinity and homophobia also in an evolutionary perspective and to dance performance: A. Ceciliani, G. Burgio, F. Buccini, M.L. Iavarone, F.I. Ambra, L. Aruta and A. Pontremoli.

The relationship between pedagogy and psychoanalysis, sufficiently addressed by highly illustrious scholars from the beginning of the twentieth century and considered here under the lens of desire and between limit and need: M. Corsi and M. Ilardo. 
Family pedagogy, parental education and counselling and homeschooling in this regard: F. Paone, A. Chinazzi and M. Stramaglia.

The pedagogy of work in its various forms, including the most technologically advanced forms, from intelligent machines to employabilities and soft skills, up to university learning, with reference nevertheless to mentoring, apprenticeships and youth employment: M. Costa, C. Pignalberi and S. Rizzari.

The educating city: F. d'Aniello; and the role, or the influence, of the mass media in general on society, schools and various educational agencies, and therefore on the integrated education system in its complexity: E.M. Bruni.

The pedagogy of inclusion, scholastic (including in relation to the manifestation or the different phenomenology of bullying), and cultural and literary: V. Rossini, F. Pizzolorusso, M. Sannipoli and E. Miatto.

Teaching and didactics, with due openness to the boundaries of reflective teacher training, the capability approach and digital skills training, as well as in alternative augmentative communication systems for students with cognitive disabilities: A. Cunti, A. Priore, G. Cappuccio, M. Albanese, L. Maniscalco, S. Fontana and S. Polenta.

Studies on corporeality in a broad sense, also in the light of the contributions of neuro-pedagogy and neuro-didactics and against the background of motor science, and as far as the fields of affectivity and sexuality in illustrated books, to deconstruct stereotypes as much as possible and prejudices: S. Bellantonio and S. Fierli.

The scope of educational policies: L. Girotti.

Like that of social pedagogy in its different perspectives and as far as the boundaries of global education and citizenship education: R. Deluigi and L. Milani.

And last, but not least, the vast area of intercultural pedagogy also in a European but still scholastic key: S. Sani.

A vast kaleidoscope, therefore, of research trends, research perspectives and pedagogical-educational proposals around which to pause carefully and critically in the pages of this booklet. Which refer, openly or not, also to other lines of research. And whose comprehensive bibliography, cited there in support of the theses that are brought, further opens up to an entire heuristic world that, all together, represents today's Italian and world pedagogy, with the challenges of the present.

That what will happen tomorrow, within our disciplines, is history, perhaps or surely, to be read and, upstream, to be written. In the very fast changing times that concerns us. Or, times that even hang over us. 